\title{
O trabalho profissional das assistentes sociais na arena antiproibicionista às drogas
}

The professional work of social workers in the antiprohibitionist arena

\author{
Priscilla dos Santos Peixoto Borelli Tavares* \\ Rita de Cássia Cavalcante Lima**
}

\begin{abstract}
Resumo - Este artigo trata o trabalho profissional de assistentes sociais vinculadas aos Caps-AD II e III do município do Rio de Janeiro, enquanto parte do movimento de resistência antiproibicionista ao giro conservador da nova política nacional sobre drogas e sua desvinculação da política de saúde mental. Discutem-se quatro questões advindas de dissertação em que foram entrevistadas oito assistentes sociais: a relação entre as expressões da questão social, o racismo e a questão de gênero; o caráter participativo no processo de trabalho na saúde mental; o terapêutico como acesso aos direitos e o trabalho territorial nos Caps-AD. O proibicionismo às drogas e sua relação com o racismo estrutural compareceram nas expressões da questão social, bem como a valorização da redução de danos, dos espaços coletivos e da circulação socioespacial pela cidade, o que vai de encontro à monoterapia da abstinência às drogas e do isolamento como condição para o cuidado.

Palavras-chave: Serviço Social; saúde mental; política de drogas; antiproibicionismo; território.
\end{abstract}

\begin{abstract}
This article deals with the professional work of social workers linked to Psychosocial Care Centers for Alcohol and Other Drugs (CAPSad) II and III in the city of Rio de Janeiro, as part of the antiprohibitionist resistance movement to the conservative New National Drug Policy and its detachment from mental health policies. It discusses four issues arising from a dissertation in which eight social workers were interviewed about the relationship between the expressions of social, race, and gender issues; the participative character of the work process in mental health; the therapeutic as access to rights; and territorial work in the CAPSad. Drug prohibitionism and its relationship with structural racism appeared in the expressions of the social issue, as well as in the appreciation for harm reduction, collective spaces, and socio-spatial circulation throughout the city, which goes against the monotherapy of abstinence from drugs and isolation as a condition for care.

Keywords: social work; mental health; drug policy; antiprohibitionism; territory.
\end{abstract}

\footnotetext{
* Mestre em Serviço Social, Coordenadora técnica CAPS III. E-mail: srbpriscilla@gmail.com. ORCID: https://orcid.org/ 0000-0001-6503-3944.

** Doutora em Serviço Social, Professora Associada da Escola de Serviço Social da UFRJ. E-mail: ritacavalcan te69@gmail.com. ORCID: https://orcid.org/0000-0001-9918-7503.
} 


\section{Introdução}

Este artigo discute respostas profissionais das assistentes sociais em serviços de base comunitária, desenvolvidas no âmbito do Sistema Único de Saúde (SUS) para pessoas com consumos nocivos de álcool e outras drogas, acompanhadas por equipes de Centros de Atenção Psicossocial, no caso, os Caps-AD. Essa escolha se deu face à potência do cuidado em liberdade para um indivíduo socialmente tomado como perigoso, seja pelas consequências diretas do proibicionismo às drogas, assentado a partir do racismo estrutural (ALBUQUERQUE, 2018), seja pela presença de dispositivos assistenciais tradicionais que condicionam o cuidado ao isolamento do usuário e à monoterapia da abstinência às drogas.

No Brasil, desde 2017, mudanças estão em curso na esfera do Executivo e do Legislativo federais, demarcando a edificação de uma nova política de drogas desvinculada da saúde mental e convocando-a somente de forma complementar. Esse giro institucional e político expressa uma contrarreforma mais ampla na política de saúde pública e, em particular, na saúde mental; ao mesmo tempo, faz "avançar" o cuidado das pessoas com consumos prejudiciais de álcool e outras drogas para comunidades terapêuticas, onde a circulação socioespacial não é preconizada. Segundo Pires, Santos e Rosa (2021), haveria benefícios terapêuticos, culturais e estéticos no cuidado de base territorial, na medida em que se promove a circulação destes sujeitos por redes comunitárias, institucionais e intersubjetivas, a fim de restituir direitos e mitigar o preconceito e a discriminação associados à ilicitude de certas drogas, gerando efeitos de tolerância e compartilhamento no uso de espaços públicos como museus, exposições, escolas, eventos etc.

Este artigo se coloca, então, em uma conjuntura desafiadora para as políticas sociais públicas, como a saúde mental, e para a democracia brasileira. De um lado, temos a aliança entre os atuais gestores federais, as lideranças das comunidades terapêuticas e a psiquiatria tradicional reorientando e distanciando a política de drogas do SUS; e, de outro, as lideranças da saúde mental e dos direitos humanos denunciando e resistindo ao giro regressivo dos direitos e ao fortalecimento da velha orientação assistencial de asilamento.

Nesse contexto, o objetivo do artigo, ao problematizar as respostas profissionais das assistentes sociais nos Caps-AD, permite apreender a direção impressa no trabalho alinhada às resistências antiproibicionista e antimanicomial. A dissertação "O trabalho profissional da assistente social nos

\footnotetext{
${ }^{1}$ Para a dissertação, como critério de inclusão, foi considerado estar a profissional vinculada ou ter estado por pelo menos um ano de trabalho. Assim, neste artigo, considerando o número pequeno de Caps-AD e de assistentes sociais, qualquer citação direta das respostas das entrevistadas será apenas codificada como "assistente social de Caps$\mathrm{AD}^{\prime \prime}$, a fim de garantir o seu anonimato (TAVARES, 2020).
} 


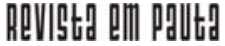

\} O TRABALHO PROFISSIONAL - TAVARES, P. S. P. B.; LIMA, R. C. C.

DOI: $10.12957 /$ REP.2022.63452

Centros de Atenção Psicossocial álcool e outras drogas - Caps-AD no município do Rio de Janeiro" (TAVARES, 2020), na qual este trabalho se baseia, entrevistou oito assistentes sociais num universo total de dez profissionais do Serviço Social e distribuídas por quatro Caps-AD no município do Rio de Janeiro. A pesquisa contou com a aprovação dos comitês de ética em pesquisa da universidade e da prefeitura do Rio de Janeiro - pareceres $\mathrm{n}^{-}$ 3.674.243 e 3.908.544, respectivamente.

Neste artigo, serão tratadas as seguintes questões advindas da análise do trabalho de campo desenvolvido com oito entrevistadas: ${ }^{1}$ a apreensão dada às expressões da questão social e sua consciente relação com o racismo e a questão de gênero; o fomento estratégico da participação dos trabalhadores, usuários e familiares para a saúde mental; a articulação elaborada entre o acesso aos direitos e o que se toma como terapêutico; e, por fim, a escolha profissional por um trabalho territorializado no processo de trabalho dos Caps-AD.

\section{Aproximações conjunturais à arena antiproibicionista}

Do Serviço Social, advém uma recente contribuição à recuperação do movimento antiproibicionista brasileiro, compreendendo-o como processo de resistências e de lutas contra-hegemônicas. Para Leal (2021), o histórico desse movimento heterogêneo aponta que não houve um enfrentamento concreto à proibição das drogas tornadas ilícitas, quando se recuperam as alterações legislativas e normativas brasileiras. Mesmo considerando as medidas do Ministério da Saúde na primeira década dos anos 2000, quando pessoas com consumos nocivos de drogas foram tomadas como sujeitos do cuidado da saúde mental, e a saúde pública passou a disputar a liderança dessa política, os serviços territorializados do SUS seguiram com recursos insuficientes para a universalização do acesso, bem como não houve consolidação de uma outra proposta de cuidado diferente das tradicionais instituições de confinamento.

A posição de Leal (2021) conflui com as análises que advertem sobre a lógica do gasto com saúde no Brasil, se considerada a comparação entre os recursos alocados no SUS e no setor privado. "No Brasil, 54\% do gasto em saúde acontece no setor privado, que atende a apenas $25 \%$ da população. O SUS, exclusivamente responsável por $75 \%$ da população, além de realizar serviços voltados para toda a sociedade, conta com apenas $46 \%$ dos recursos" (CAMPOS, 2018, p. 1708). Desta forma, os patamares de investimento em saúde pública são insuficientes para uma universalização do acesso e para uma qualidade dos serviços cujo orçamento foi agravado com o ajuste fiscal definido pela Emenda Constitucional no 95, de 2016 (EC no 95/2016), período imediatamente posterior à destituição da presidenta Dilma Rousseff. Essa emenda congelou os gastos da União 
com despesas primárias entre 2017 e 2036, corrigidos pela inflação medida pelo IPCA, sendo o SUS um dos setores atingidos.

No caso da política nacional de saúde mental, álcool e outras drogas, as duas décadas dos anos 2000 apresentaram tendências distintas. Segundo Weber (2021), entre 2001 e 2009, houve crescimento real de $51,2 \%$ dos recursos investidos em saúde mental, devendo-se ressaltar que se tratou do período em que houve o redirecionamento da assistência em saúde mental para fortalecer os serviços extra-hospitalares, mesmo com o subfinanciamento do SUS. Já entre os anos 2010 e 2019, a mesma autora identificou queda de $14,7 \%$ e estabilização dos gastos do Fundo Nacional de Saúde com a saúde mental, em especial a partir de 2016, quando o desfinanciamento ao SUS já se colocava e foi aprofundado com a EC no 95/2016.

Se essas informações corroboram para darmos relevo aos impactos do aprofundamento da agenda neoliberal na política social de saúde, a saúde mental, em seu interior, também revela outra tendência ao desfinanciamento do SUS. Há mudanças na direção do modelo assistencial na saúde mental e na atualização do antigo regime de atenção aos consumidores de álcool e outras drogas, quando se privilegia o afastamento desse usuário de sua circulação socioespacial, sempre tomada como território disparador de danos. Isso implica o fortalecimento da tendência de que tratar pessoas que consomem álcool e outras drogas seja necessariamente afastá-los do acesso às drogas não prescritas e, também, da convivência familiar e comunitária.

Devemos lembrar que, antes do movimento da reforma psiquiátrica brasileira, o financiamento público para leitos em hospitais psiquiátricos gerou o que foi conhecido como porta giratória ou revolving door. Tratava-se de uma consequência do desenho da política (GASTAL, 2000). No caso da atual política de drogas, a decisão de financiar leitos em comunidades terapêuticas pode conformar outra porta giratória, considerando que o fluxo assistencial preveja o manejo de cada reincidência no consumo das substâncias psicoativas como indicação para referenciar entradas naquelas instituições e, também, nos hospitais psiquiátricos.

Portanto, a partir de 2017, o crescente financiamento público de leitos nas comunidades terapêuticas, em sua maioria religiosas (IPEA, 2017), foi acompanhado do desfinanciamento dos serviços de base comunitária da Rede de Atenção Psicossocial (Raps) organizados no âmbito do SUS, ao mesmo tempo que fez adentrar os dispositivos do hospital e do ambulatório da psiquiatria nessa rede. Portanto, não se trata apenas da redução do investimento na saúde pública, mas da reorientação das finalidades e do retorno de serviços que foram objeto da crítica da reforma psiquiátrica. Ademais, revisitar o pretérito faculta reconhecer que a trajetória de fortalecimento das comunidades terapêuticas religiosas foi processual e se deu concomitantemente à ampliação da rede extra-hospitalar na saúde mental na primeira década dos anos 2000, porém, por esferas fora do SUS. 
Como não recordar o II Fórum Nacional Antidrogas realizado em Brasília, em 2001, durante a III Conferência Nacional de Saúde Mental (LIMA; TAVARES, 2012) Enquanto neste espaço do controle social, a atenção às pessoas com consumos prejudiciais de álcool e outras drogas foi discutida e deliberada para ser disponibilizada pelo SUS; no outro evento consultivo, com a presença do ex-presidente Fernando Henrique Cardoso, foi apresentada a política nacional antidrogas.

$\mathrm{Na}$ atualidade, as comunidades terapêuticas passaram a integrar três sistemas nacionais, cada qual com o seu fundo de financiamento, a saber: no SUS, desde a institucionalidade da Raps, em 2011, e também com a alteração realizada na Portaria no 3.588, de 2017; no Sistema Nacional de Políticas Públicas sobre Drogas (Sisnad), através da Lei no 13.840, de 2019; e, mais recentemente, no Sistema Único de Assistência Social, através da Portaria Conjunta $n^{\circ}$ 4, de 2020, que inseriu as comunidades terapêuticas também na rede socioassistencial.

Portanto, o Brasil se encontra, no momento, com uma nova política nacional sobre drogas, de caráter oficial, mas mantém forças que resistem ao giro regressivo da política de saúde mental e à naturalização dos efeitos do proibicionismo, cuja assistência às pessoas com consumos prejudiciais de álcool e outras drogas é condicionada por essa arena de luta. O objetivo deste artigo, então, vai na direção de reconhecer essas forças antiproibicionistas no cotidiano do trabalho profissional da saúde mental, a qual edificou um novo mirante ético e político do cuidado em saúde, reconhecendo que o uso das drogas é um fenômeno trans-histórico, objeto da saúde pública, dos direitos humanos e da redução de danos (BRITES, 2017); e demanda do trabalho das assistentes sociais em Caps-AD (ALBUQUERQUE; LANDIM; ANDRADE, 2018).

\section{O trabalho profissional das assistentes sociais nos Caps-AD}

A reforma psiquiátrica brasileira modificou o cuidado em saúde mental, outrora centrado no saber e no poder da psiquiatria, e valorizou o trabalho interprofissional. O Serviço Social compõe as equipes de muitos serviços da Raps, dentre eles, os Caps-AD, cujo trabalho profissional pode contribuir para a defesa do direito constitucional de autodeterminação dos usuários de drogas, para o trabalho no combate de qualquer tipo de preconceito. Além disso, ainda traz para o debate os impactos do proibicionismo sobre as expressões da questão social e do reforço à estratégia de redução de danos enquanto orientadora do tratamento (CFESS, 2019).

A articulação entre a saúde mental e o Serviço Social é antiga, e sua interlocução com o marxismo e com correntes que abordam a subjetividade foi discutida por Duarte (2010) e Vasconcelos (2016), enfrentando a crítica à psicologização das expressões da questão social como tendência 
do capitalismo monopolista e a redução operada pela abordagem conservadora da psicologia do ego no Serviço Social tradicional. Segundo o autor, há o desafio de a profissão articular a temática da subjetividade em sua agenda ética e política, irrigando o debate da formação e do trabalho profissional para apreender que existe uma corporeidade nos usuários, em que sua sexualidade, gênero, religiosidade, entre outros, permeiam as classes sociais.

Na arena das disputas postas nas políticas de drogas, este desafio se atualiza, na medida em que as abordagens teóricas em sua qualidade de práxis precisam desvelar essa realidade, saturada de posição de valor (BRITES, 2017), e produzir intervenções no real. Na questão das drogas (ALBUQUERQUE, 2018), destacam-se as relações sociais raciais e de gênero, visto que a violência institucional no mercado das drogas ilícitas é usada para legitimar a necropolítica estatal e as relações sociais desiguais de gênero. O destaque dessas questões não as retira da perspectiva da totalidade inserida na luta de classes entre capital e trabalho, mas reconhece que, na busca da igualdade, as lutas contra o machismo e o racismo são imprescindíveis.

Assim, a partir desse mirante analítico, cotejemos as questões extraídas da análise do trabalho de campo da dissertação"O trabalho profissional da assistente social nos Centros de Atenção Psicossocial álcool e outras drogas - Caps-AD no município do Rio de Janeiro" (TAVARES, 2020) .

\section{As relações sociais de raça e gênero nas expressões da questão social}

A colonização e a escravidão nas Américas estruturam-se na hierarquização entre colonizadores e colonizados, justificada pela ideia de raça, que coloca os africanos escravizados e os nativos do continente em condições de inferioridade tomadas como naturais em relação aos europeus. É esta falácia que fundamenta as relações de dominação colonial e que se cristaliza ideologicamente, mesmo após a independência das colônias (QUIJANO, 2005).

Considerar esses componentes permite identificar a determinação do racismo estrutural no trato da criminalização da questão das drogas no país, e essa relação foi identificada pelas entrevistadas a partir do cuidado em saúde.

Ah, com certeza, é o proibicionismo, [...] é uma forma de criminalização [...] do uso de algumas substâncias, mesmo porque o público que a gente atende no serviço, em sua maioria pobre, majoritariamente negro, que facilmente são vistos pela política de segurança mesmo como criminosos, embora muitas vezes sejam só usuários [...]. A política de segurança e de saúde são muito antagônicas e, 
por vezes, é difícil conciliar essas políticas que estão vigentes. (Assistente social de Caps-AD).

O encarceramento e o assassinato da população negra no país são efeitos do racismo estrutural e justificados pelo proibicionismo às drogas, sendo esse o solo do trabalho profissional das assistentes sociais na saúde mental, agravado pelo cenário belicista existente no Rio de Janeiro (ROCHA; LIMA; FERRUGEM, 2021). Também nessa direção, para Silva e Marques Jr. (2020), a "guerra às drogas" é uma estratégia de continuidade do racismo estrutural e da antinegritude, pois associa o lugar do traficante àquele que já era considerado como criminoso; da mesma forma, coloca os negros como alvo principal das políticas de segurança, e não como prioridade das políticas de saúde e de saúde mental. "[...] Uma escuta mais atenta ao sofrimento causado pela questão de raça e cultura e até mesmo relacionado à questão da identificação sexual é muito forte no serviço aos usuários de saúde mental que eu atendo" (Assistente social de Caps-AD).

No que tange às mulheres negras, o racismo se articula com a opressão do patriarcado e precisa ser considerado no cuidado às usuárias dos serviços de saúde mental. Segundo Cisne (2015), é fundamental não reforçar nas mulheres as funções definidas pelo patriarcado, visto que são fruto de um processo histórico e cultural de construção de valores, saberes e práticas por uma concepção diferente sobre os sexos. A marca feminina é criada de acordo com os interesses da classe dominante, resultante da produção de desigualdade entre mulheres e homens.

Destacamos na pesquisa, como elemento importante para o trabalho da assistente social no Caps-AD, as violências relatadas pelas mulheres que chegam ao serviço. Essa violência muitas vezes está intrinsecamente relacionada à expectativa de minorar os danos com o uso das drogas e, em outros momentos, coloca essas mulheres em situações de maior risco e danos. Para Almeida (2007), a violência de gênero é produzida no contexto das relações sociais que se expressam no marco da produção e reprodução das relações fundamentais de classe, gênero e étnico-raciais. Em vista disso, é estrutural nas relações sociais capitalistas e sua vivência tem impactos nos serviços de saúde, já que leva à busca pela medicalização de um sofrimento cuja determinação se coloca na órbita da produção e da reprodução das relações sociais vigentes.

As desigualdades de classe, de raça e de gênero, portanto, colaboram para ampliar os danos sociais e à saúde na população atendida na saúde mental e são atualizadas e agravadas quando associadas ao consumo das drogas ilícitas na saúde mental. Essa relação complexa, no entanto, compareceu na apreensão das entrevistadas, que a tomam como constitutiva das expressões da questão social, seu objeto cotidiano do trabalho profissional. 


\section{A participação como resposta profissional e orientação da luta antiproibicionista}

A participação em espaços coletivos nos Caps-AD e em mobilizações sociais foi relatada pelas oito entrevistadas. Apesar de o fomento à participação dos trabalhadores, usuários e familiares não ser uma atribuição privativa das assistentes sociais, é esta profissão que pareceu dispor de maior aporte ético-político, teórico-metodológico e técnico-operativo para fomentá-la nesses espaços sócio-ocupacionais (ALBURQUERQUE; LANDIM; ANDRADE, 2018). Essa participação ocorreu em espaços grupais dentro das unidades, que fortaleciam o debate político com usuários e familiares, como destacado pela entrevistada: "[...] a gente construiu coisas muito legais nas assembleias, mas a galera ficou com ódio de saber coisas sobre direito e não conseguir acessá-las" (Assistente social de Caps-AD).

As assembleias são espaços históricos dos serviços da saúde mental, com participação de profissionais, usuários e familiares, para discussão e deliberação de assuntos que vão desde situações do funcionamento dos serviços, à análise de conjuntura, à socialização de orientação quanto ao acesso aos direitos, à articulação de participação em movimentos coletivos, entre outros. Elas acontecem em periodicidade regular e suas pautas são construídas coletivamente entre os participantes. São espaços fundamentais para fomentar o conhecimento da realidade institucional e social e exercitar uma prática política coletiva na direção do controle social do SUS e outros direitos sociais.

Além das assembleias, as profissionais referiram participar de espaços de mobilização com os usuários, ampliando a circulação socioespacial:

A gente fazia ocupações mensais nas praças da cidade, assim como eventos na universidade abertos ao público; tanto explicando o que é esse serviço, a importância do Caps [...]. Assim como as assembleias fora do espaço do Caps, atos pela cidade do Rio de Janeiro, por exemplo, em frente ao Tribunal Regional do Trabalho. (Assistente social de Caps-AD).

Nessa expansão do uso dos territórios, a agenda de pautas importantes incluiu a participação em movimentos contra a privatização da saúde e a favor da luta antimanicomial. Observou-se, assim, que as entrevistadas valorizam os espaços coletivos no trabalho profissional enquanto ações táticas de mobilização social que articulam trabalhadores, familiares e usuários, a fim de desvendar as determinações que os impedem de acessar direitos e de organizar sua resposta coletiva.

[...] a gente precisa discutir com esse usuário que sociedade é essa, que Estado é esse e que política está sendo viabilizada de fato. Porque, às vezes, tem um imaginário como se fosse um acesso mais ampliado, 
como uma garantia de direito, quando a gente sabe que, de fato, as políticas estão cada vez mais restritivas. Então, esse trabalho do Serviço Social tem elementos tanto teóricos, quanto para pensar a realidade social junto com esse usuário, para ter uma visão crítica dessa política, mas também de construir os encaminhamentos junto com eles e com a equipe do que existe, para pensar esse recurso que existe de fato. (Assistente social de Caps-AD).

Na pesquisa, observou-se a realização de grupos facilitados pelas assistentes sociais, com as seguintes demandas: a questão de gênero no grupo das mulheres; a precarização do trabalho; o acesso aos direitos sociais, à cidade e à cultura nos grupos de poesia, sarau e contos. Em relação ao último, uma das entrevistadas destacou a importância de o Serviço Social se aproximar desses espaços, já que "a gente pouco encara isso como um direito, arte e cultura" (Assistente social de Caps-AD), o que vai ao encontro da análise de Pires, Santos e Rosa (2021), ao referirem os benefícios terapêuticos, culturais e estéticos da circulação socioespacial.

Em um contexto de avanço neoliberal, é essencial que as assistentes sociais ocupem e fomentem espaços coletivos de mobilização social, reforçando uma articulação política permanente no âmbito da sociedade civil, articulando estratégias comuns para o fortalecimento da democracia (IAMAMOTO, 2012). Portanto, em período de ofensiva e desfinanciamento dos serviços de base comunitária para o cuidado de usuários de drogas, observar a sustentação e a escolha profissional de assistentes sociais em Caps-AD por um trabalho cotidiano de fomento à participação e à organização coletiva indica uma visão estratégica do trabalho profissional, orientada por princípios do código de ética profissional, cujos valores vão ao encontro de tendências da luta antiproibicionista, que defende a radicalidade de valores como a liberdade, os direitos humanos, o não preconceito e tampouco a discriminação de qualquer ordem.

\section{"Garantir direito é terapêutico!"}

A frase título deste tópico foi dita por uma das entrevistadas, ao apontar o que nomeia de "encarceramento da rua", em contraste com o senso comum de que a população em situação de rua dispõe de uma liberdade de circulação socioespacial. Ao mesmo tempo, retomou o reconhecimento de que, embora não seja competência das assistentes sociais fazer terapia, a atenção à garantia dos direitos sociais e humanos torna as ações profissionais terapêuticas.

Eu acho que quando a gente fala em pessoa em situação de rua; quando a gente sai com a pessoa para garantir alguma coisa, é uma atividade terapêutica, pois estar na rua não significa que eles circulam 


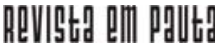

\} O TRABALHO PROFISSIONAL - TAVARES, P. S. P. B.; LIMA, R. C. C. \}

DOI: $10.12957 /$ REP.2022.63452

em todos os espaços. Assim, às vezes, sair com ele do Caps e o simples fato de ir ao Cras, eu avalio como terapêutico, sim! E ele entender que pode acessar alguns serviços! Que ele saia um pouco do encarceramento da rua, porque é isso: você fica preso na rua, mas não consegue circular nos espaços para garantir seus direitos, fazer algum outro tipo de circulação. (Assistente social de Caps-AD).

A entrevistada demonstrou que o acesso aos direitos como terapêutico impõe a relação orgânica entre a esfera da objetividade e da subjetividade, não sendo possível dissociá-las, nem homogeneizá-las. A concepção de sofrimento dos usuários dos Caps-AD parece se inserir neste encontro.

De um usuário, quando a gente estava na roda de cidadania, discutindo sobre racismo; ele falou: 'eu não sabia que a gente ia falar disso aqui no Caps e isso me traz um sofrimento enorme' [..]. Eu acho que quando um usuário em situação de pobreza extrema acessa um benefício que vai lhe dar uma maior qualidade de vida, não é uma terapia, mas tem um efeito terapêutico para ele. (Assistente social de Caps-AD).

O trabalho com grupo se torna ele próprio, então, uma ação terapêutica, na medida em que aposta na construção coletiva de educação em saúde e de reflexão crítica ao racismo estrutural, às questões de gênero, trabalho, acesso à cidade, às políticas sociais etc. Falar sobre as precárias condições de vida dos usuários e de sua produção social possibilita um deslocamento dos discursos de culpabilização de que foram acusados em suas trajetórias de vida. $\mathrm{O}$ reconhecimento de serem indivíduos singulares e sociais em período de ofensiva neoliberal também os permite declinar expectativas sobre uma provisão paternal de direitos por parte do Estado brasileiro (BARRETO; DUARTE, 2018) e os convida a participar de outros espaços coletivos.

A relação entre direitos e o terapêutico também compareceu a partir da orientação da redução de danos no trabalho profissional das entrevistadas, quando expressaram a responsabilidade do cuidado enquanto uma resposta implicada com a luta de classes, gerando preocupação com os desafios para se guiar pela defesa da autonomia dos usuários e da liberdade particularmente, em contextos sociais que reduzem os meios para os indivíduos realizarem escolhas.

[...] Eu acho que, com o enfrentamento das expressões da questão social, o enfrentamento à miserabilidade, à violência [...]. Eu acho que a [...] a redução de danos tem relação com a luta de classe, assim, tem tudo a ver, a gente pode pensar redução de danos até para quem não faz uso de álcool e outras drogas. Assim, por pensar a redução de danos através disso [...] ser uma lógica de vida de singularidade, de respeito à liberdade, à autonomia, mas é um respeito que não é um respeito se eximindo de nenhuma responsabilidade, 
do cuidado; é o respeito de construir um cuidado possível para as pessoas [...]. (Assistente social de Caps-AD).

O proibicionismo e o consequente mercado ilegal das drogas se tornam um meio para frações da classe trabalhadora serem encarceradas e mortas através do uso sistemático da violência do Estado, sendo arena por onde se manifesta a barbárie da sociabilidade burguesa, através de intervenções conservadoras orientadas pelos interesses do capital (BRITES, 2017). Portanto, o posicionamento consciente das entrevistadas em orientar o trabalho profissional na perspectiva da redução de danos fortalece a agenda antiproibicionista.

\section{O trabalho profissional em territórios psicotrópicos}

As assistentes sociais entrevistadas referiram ir sistematicamente ao encontro dos usuários de drogas em territórios conhecidos pelo consumo e venda de drogas, onde circulam desde consumidores esporádicos até aqueles nos quais a droga já ganhou maior centralidade na vida, o que é expresso pela maior permanência no espaço; há mesmo alguns que passaram a morar lá. Mata e Fernandes (2019) os nomeiam de "territórios psicotrópicos", lugares onde os demais moradores da cidade tendem a não frequentar, o que gera temor e ignorância sobre quem neles habita, suas relações com as drogas e as práticas de socialização e de trabalho que lá são produzidas.

Esta noção foi cunhada pelo professor Luís Fernandes, a partir dos estudos etnográficos realizados em espaços de consumos abertos de drogas nas cidades de Lisboa e do Porto, nos anos 1990. A adjetivação do território como psicotrópico se inseriu no movimento maior de redemocratização do país e de descriminalização de certas práticas de consumos de drogas em Portugal, fortalecendo a saúde pública na direção da política de drogas e ofertando àquelas pessoas um conjunto de acesso aos direitos sociais, como moradia, trabalho, tratamento, redução de danos, dentre outros serviços (FERNANDES, 1995).

Então, era um trabalho, uma semana em uma cena de uso grande e conhecida pelos usuários do Caps. Era um lugar que a gente já sabia que existia. Era muito, muito, muito precário! As condições eram insalubres e a gente chegou oferecendo cuidados em saúde, não necessariamente relacionadas ao uso, já que era um lugar muito, muito, muito insalubre [...]. (Assistente social de Caps-AD).

Em relação às atividades desenvolvidas nesses territórios, as entrevistadas referiram desenvolvê-las com outros profissionais e, por vezes, de forma intersetorial, distribuindo insumos como preservativos e lanches e realizando atendimentos diversos de saúde, bem como atividades lúdicas. 
[...] a gente oferece esse lanche na parte da tarde e, aí, a gente faz a abordagem [...] - questiona o que aquela pessoa está precisando naquela semana, como ela está. A gente faz acolhimento às situações de crise, ali, e acompanhamento longitudinal também, porque são pessoas que não chegariam ao Caps, em nenhum Caps, nem Caps II e nem no $A D$, nem nos demais serviços. Então, por exemplo, tem casos que eu já acompanho nessa cena de uso há dois anos, [...] e, ali, a gente vai fazendo as ações para que esse cuidado seja cada vez mais eficaz [...]. A gente articula com o agente comunitário para que vá ver a pessoa durante a semana, caso ela tenha alguma demanda clínica; com o Cras ou com o Creas, caso essa pessoa precise de algum documento, que isso seja organizado junto [...]. (Assistente social de Caps-AD).

O trabalho territorial com mulheres usuárias de drogas nos CapsAD passa por identificar e atuar sobre as violências vivenciadas diariamente por elas, de forma que o uso que realizam não se torne cada vez mais uma barreira de acesso aos direitos e justifique sua discriminação. Estar nos territórios psicotrópicos, por exemplo, é essencial, pois observamos as dificuldades dessas mulheres em acessar os Caps-AD. Segundo as entrevistadas, a aproximação com elas se dá muitas vezes questionando se necessitam de algum suporte para acesso à atenção básica e à distribuição de manteiga de cacau e de preservativo. A abordagem sobre as infecções sexualmente transmissíveis e o uso de drogas, quando colocado por elas como uma questão, normalmente está vinculada às violações sistemáticas de direitos e à violência como um fenômeno recorrente.

A sustentação de um cuidado no território psicotrópico (MATA; FERNANDES, 2019), segundo as entrevistadas, então, se contrapõe à lógica do necessário isolamento para a provisão do cuidado e da monoterapia da abstinência às drogas como condição e meta exclusiva do projeto de trabalho em saúde. Esta sustentação também vai de encontro à necropolítica do Estado, visto que permite acesso a políticas intersetoriais a uma população de maioria negra que é vista enquanto sujeitos perigosos e suscetíveis apenas ao encarceramento e ao assassinato justificado pelo proibicionismo às drogas, sendo esse o solo do trabalho profissional das assistentes sociais entrevistadas.

Portanto, investigar esse lugar do trabalho em saúde mental para as pessoas com usos nocivos de álcool e de outras drogas permite captar os efeitos atuais da contrarreforma em curso nas políticas sociais de saúde mental, mas também a edificação da "nova" política de drogas. É na tessitura entre o velho atualizado e o novo, que resiste ao giro regressivo da conjuntura atual, que este artigo tomou o trabalho profissional das assistentes sociais nos Caps-AD do município do Rio de Janeiro como um analisador das resistências e da inventividade em curso no SUS. 


\section{Considerações finais}

A partir da análise das entrevistas, observou-se como a profissão do Serviço Social no espaço sócio-ocupacional dos Caps-AD no município do Rio de Janeiro desenvolve suas respostas a partir de um trabalho necessariamente coletivo, participativo, interprofissional e intersetorial. Este indica, desde o cotidiano do serviço de saúde mental, uma resistência e uma inventividade antiproibicionista edificada nas últimas décadas de redemocratização do Brasil e de implementação do Sistema Único de Saúde. Ao mesmo tempo, a despeito do reconhecido giro regressivo das políticas sociais públicas brasileiras, acelerado a partir de 2016, as entrevistadas apontam a vitalidade da orientação da redução de danos que converge com conhecimentos acumulados na formação do Serviço Social, fazendo-o participar das resistências e das lutas fomentadas pelos movimentos antimanicomial e antiproibicionista.

O trabalho profissional das entrevistadas nesses serviços, orientado pela redução de danos, reconhece o usuário de drogas como pertencente à classe trabalhadora e toma a intervenção regular nos territórios psicotrópicos da cidade do Rio de Janeiro como ação tática para minorar os efeitos da "guerra às drogas" e para aproximar esses sujeitos, prevalentemente negros, do acesso à saúde e a outras políticas sociais.

A reforma psiquiátrica brasileira e o movimento antiproibicionista, enquanto processo, se mantêm na órbita das referências de conhecimento acionadas para a tomada de decisões das assistentes sociais entrevistadas, o que nos faz reconhecer que a profissão, em seu acúmulo, a partir da teoria social crítica e dos valores éticos expressos em seu código de ética, se torna fecunda para resistir à naturalização do racismo estrutural e às desigualdades de gênero que compõem a questão das drogas e a moralidade tradicional.

Apesar das céleres e profundas mudanças regressivas em curso, que tomam as drogas como um ente autônomo e volitivo capaz de dissolver as famílias e afastar os indivíduos do caminho da virtude, este artigo indica que a esperança está na ordem do dia. Há forças que seguem organizadas em projetos para disputar a liderança da política de saúde mental e drogas. De um lado, os que naturalizam o proibicionsimo às drogas e seus efeitos e, de outro, os que fincam trincheiras antiproibicionistas. Ao Serviço Social, não interessa qualquer tendência do movimento antiproibicionista, que Leal (2021) tão bem examinou, mas somente a que se vincula à construção coletiva da emancipação política e humana que aposta na radicalização da democracia política e econômica. 


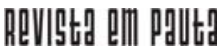

\} O TRABALHO PROFISSIONAL - TAVARES, P. S. P. B.; LIMA, R. C. C. \}

DOI: $10.12957 /$ REP.2022.63452

\section{Referências}

ALBUQUERQUE, C. S. Drogas, "questão social" e Serviço Social: respostas teórico-políticas da profissão. Tese de Doutorado(Doutorado em Serviço Social) - Escola de Serviço Social, Programa de Pós-Graduação em Serviço Social, Universidade Federal do Rio de Janeiro, Rio de Janeiro, 2018.

ALBURQUERQUE, C. S.; LANDIM, E.; ANDRADE, M. O fazer do assistente social nos Centros de Atenção Psicossocial (Caps). In: LOPES, C. (Org.). Competências e atribuições do/a assistente social: requisições e conhecimentos necessários. Fortaleza: Socialis, 2018.

ALMEIDA, S. S. de. Essa violência mal-dita. In: ALMEIDA, S. S. de. (Org.). Violência de gênero e políticas públicas. Rio de Janeiro: Editora UFRJ, 2007.

BARRETO, M. C.; DUARTE, M. J. de O. Um mais um é sempre mais que dois: o dispositivo grupal no trabalho profissional do Serviço Social no campo de álcool e outras drogas. In: BARCELLOS, W. de S.; DIAS, M. T. G.; HEIDRICH, A. V. (Org.). O exercício profissional do Serviço Social nas políticas de saúde mental e drogas. Rio de Janeiro: Lumen Juris, 2018.

BRITES, C. M. Psicoativos (drogas) e Serviço Social: uma crítica ao proibicionismo. São Paulo: Cortez, 2017.

CAMPOS, G. W. de S. SUS: o que e como fazer? Ciência e Saúde Coletiva, Rio de Janeiro, v. 23, n. 6, jun. 2018.

CFESS. As implicações das alterações na política nacional de saúde mental, álcool e outras drogas para o exercício profissional de assistentes sociais no Brasil. Brasília, jul. 2019. Disponível em: http://www.cfess.org.br/arquivos/ Nota-tecnicalei13840-2019-.pdf. Acesso em: 9 nov. 2019.

CISNE, M. Gênero, divisão sexual do trabalho e Serviço Social. São Paulo: Outras Expressões, 2015.

DUARTE, M. J. de O. Subjetividade, marxismo e Serviço Social: um ensaio crítico. Serviço Social e Sociedade, n. 101, 2010. Disponível em: https:// doi.org/10.1590/S0101-66282010000100002. Acesso em: 10 jun. 2021.

FERNANDES, L. O sítio das drogas: etnografia urbana dos territórios psicotrópicos. Revista Toxicodependência, n. 2, 1995.

GASTAL, F. L. et al. Predicting the revolving door phenomenon among patients with schizophrenic, affective disorders and non-organic psychoses. Revista de Saúde Pública, v. 34, n. 3, 2000. Disponível em: https://doi.org/ 10.1590/S0034-89102000000300011. Acesso em: 10 jun. 2021.

IAMAMOTO, M. V. Projeto profissional, espaços ocupacionais e trabalho do assistente social na atualidade. In: CFESS (Org.). Atribuições privativas do/a assistente social em questão. Brasília: CFESS, 2012. 


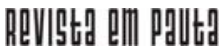

\} O TRABALHO PROFISSIONAL - TAVARES, P. S. P. B.; LIMA, R. C. C.

DOI: $10.12957 /$ REP.2022.63452

IPEA. Perfil das comunidades terapêuticas brasileiras. Brasília, 2017. Disponível em: http://www.ipea.gov.br/portal/images/stories/PDFs/nota_ tecnica/20170418_nt21.pdf. Acesso em: 26 out. 2019.

LEAL, F. X. Movimento antiproibicionista no Brasil: resistência e luta. São Paulo: Annablume, 2021.

LIMA, R. de C. C.; TAVARES, P. dos S. P. B. Desafios recentes às políticas sociais brasileiras sobre as drogas: enfrentamento ao crack e proibicionismo. Argumentum, Vitória, v. 4, n.2, p. 6-23, jul./dez. 2012

MATA, S.; FERNANDES, L. Revisitação aos atores e territórios psicotrópicos do Porto Olhares etnográficos no espaço de 20 anos. Civitas, Porto Alegre, v. 19, n. 1, jan./abr. 2019. Disponível em: https://revistaseletronicas.pucrs.br/ ojs/index.php/civitas/article/view/30648/17720. Acesso em: 20 dez. 2019.

PIRES, R. R. C.; SANTOS, M. P. G. dos; ROSA, L. L. Tendências e desafios das políticas de cuidado a usuários de drogas na América Latina. In: PIRES, R.; SANTOS, M. P. (Org.). Alternativas de cuidado a usuários de drogas na América Latina: desafios e possibilidades de ação pública. Brasília: Ipea, 2021.

QUIJANO, A. Colonialidade do poder, eurocentrismo e América Latina. In: LANDER, E. (Org.) A colonialidade do poder: eurocentrismo e as ciências sociais. Perspectivas latino-americanas. Buenos Aires: Clacso, set. 2005.

ROCHA, A. P.; LIMA, R. de C. C.; FERRUGEM, D. Autoritarismo e guerra às drogas: violência do racismo estrutural e religioso. Revista Katálysis, v. 24, 2021.

SILVA, A. P. P. da; MARQUES JR., J. S. Racismo estrutural e o paradigma antinegro: o proibicionismo e a guerra às drogas como os novos grilhões dos negros brasileiros. In: GOMES, T. M. da S.; PASSOS, R. G.; DUARTE, M. J. de O. Saúde mental e drogas em tempos de pandemia: contribuições do Serviço Social. Uberlândia: Navegando Publicações, 2020.

TAVARES, P. dos S. P. B._O trabalho profissional da assistente social nos Centros de Atenção Psicossocial álcool e outras drogas - CAPS AD no município do Rio de Janeiro. Rio de Janeiro, 2020. Dissertação (Mestrado em Serviço Social) - Escola de Serviço Social, Universidade Federal do Rio de Janeiro, Rio de Janeiro, 2020.

VASCONCELOS, E. M. Reforma psiquiátrica, tempos sombrios e resistência: diálogos com o marxismo e o Serviço Social. São Paulo: Papel Social, 2016.

WEBER, R. O financiamento público de comunidades terapêuticas: gastos federais entre 2010 e 2019. In: RUI, T.; MAURICIO, F. (Ed.). Working paper series: comunidades terapêuticas no Brasil. Brooklyn: Social Science Research Council, jun. 2021. Disponível em: https://www.ssrc.org/ 


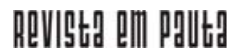

\} O TRABALHO PROFISSIONAL - TAVARES, P. S. P. B.; LIMA, R. C. C. \}

DOI: $10.12957 /$ REP.2022.63452

publications/view/working-paper-series-comunidades-terapeuticas-nobrasil/. Acesso em: 21 jun. 2021.

DOI: $10.12957 /$ rep.2022.63452

Recebido em 03 de julho de 2021.

Aprovado para publicação em 03 de setembro de 2021.

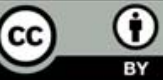

A Revista Em Pauta: Teoria Social e Realidade Contemporânea está licenciada com uma Licença Creative Commons Atribuição 4.0 Internacional. 